\title{
Preliminary results on identification of bacterial flora from the saliva of bats in Algeria.
}

\author{
Louhibi N. $^{1}$ Kerboub Y. ${ }^{1}$ Vitale M. $^{2}$ Gaouar S.B.S. ${ }^{1}$ \\ ${ }^{1}$ Laboratory of Applied Genetics in Agronomy, Ecology and Public Health, SNV / STU \\ Faculty, University of Tlemcen \\ ${ }^{2}$ Microorganisms laboratory, Institut experimentale en zooprofilaxie of Sicily
}

Corresponding author: Pr. Gaouar Suheil, University of Tlemcen, Algeria, Email: suheilgaouar@gmail.com

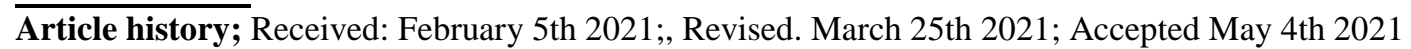

Abstract

Bats are among the most remarkable mammals with extraordinary adaptations. They play a key role in the ecosystem. It is well known that bats are also reservoirs for many viruses. However, their bacterial flora is relatively less explored. According to our bibliographic research, very little work has been carried out on the saliva of bats. The present study describes the microbial diversity associated with the saliva of two species of bats (Myotis Punicus and Rhinolophes ferrumequinum) in Sebdou region (Tlemcen), Algeria. The microbiological, biochemical and molecular examination of the bat saliva allowed to identify 14bacterialgenera:Pseudomonas, $\quad$ Chryseomonasluteola, Staphylococcus spp., Shigella, Raoultellaornithinolytica, Enterobacter cloacae, Enteratia fudicariaii, Serrobatia fudicariaii, odorifera, Suterobacter cloacoe, Suterobacter sakazakii, Salmonella charizonae, Salmonella choleraesuis ssp arizone, Klebsiella oxytoca, Proteus Mirabilis and Yersinia. This report give some preliminary results on the microbiota diversity associated with the oral cavity and the saliva of two species of bats, sampled in a determinedregion of Algeria.
\end{abstract}

Keywords: Tlemcen (Sebdou), Bat, saliva, identification, genomic, micro-organism.

\section{Introduction}

Bats represent a third of Algerian species of mammals, but they are among the most endangered in our country. These animals are little known to the public and are the subject to beliefs and superstitions. Therefore, if in India and China these animals are a sign of happiness and luck, in Europe many still believe that they cling to women's hair that they bite on the neck to suck blood and that they bring bad luck.

There is a widevariety of sizes, shapes and colors. The smallest bat weighs around $5 \mathrm{~g}$ and the largest can reach $40 \mathrm{~g}$ of weight. Among the Megachiroptera,which are not reported in Europe, the biggest species is the giant fruit bat of the Samoan Islands can reach a wingspan of $2 \mathrm{~m}$ and a weight of $1.5 \mathrm{~kg}$, (Arthur and Lemaire, 1999).

Chiroptera (bats) can harbor many bacteria. Among the faecal flora, many speciessuch as Citrobacter freundii, Klebsiella oxytoca and Proteus morganii have been reported to be mostly oportunistic microorganisms. On the other hand, Escherichia Coli and Proteus mirabilis are considered as primary agents of infection of the urinary and digestive tract. However, their presence is common in the digestive tract of all mammals (Guangwen and Di, 2012; Chastel, 2014; O'Shea et al., 2014). Microorganisms play a crucial role in maintaining the delicate ecological balance of the earth. They revitalize the soil by recycling minerals and nutrients from decaying material, and many are essential for healthy plant growth. Microorganisms also affect our daily lives through the production of food products, detergents, antibiotics and anti-tumor drugs (Bertrand et al., 2011).. 
Bacteria found in the intestinal tract of mammals play an important role in the breakdown and digestion of food. These organisms have an enzyme with a capacity of breaking down a wide variety of substances. Until recently, very little research has been done on the microbial ecology of such an environment. The potential benefits of this type of studies are huge (Lutz et al., 2019). A symbiosis exists between these organisms and bats.

Research in the field of the microbiome focuses on extreme environments (of which caves are a part) based on the assumption that such environments are enriched with new microorganisms. (Lutz et al., 2019).

\section{Materials and methods}

\section{Geographical location of the sampling site}

During our work we have exploited several caves to finally choose the site of Dermam commune of Sebdou: itis a natural cave which is located in a very steep region at mountain level and in a semi-arid zone; this cave is more than $300 \mathrm{~m}$ deep and no investigations have been carried out so far in this site. The municipality of Sebdou is one of the municipalities of the Wilaya of Tlemcen, it is commonly called "the southern gate" since it forms a real link between the north of the Wilaya and its steppe area. The commune of Sebdou covers a total area of $250 \mathrm{~km} 2$; it is located on the road axis of the R.N. No. 22 , which is known as a very dynamic corridor in the North-South trade of populationand goods.

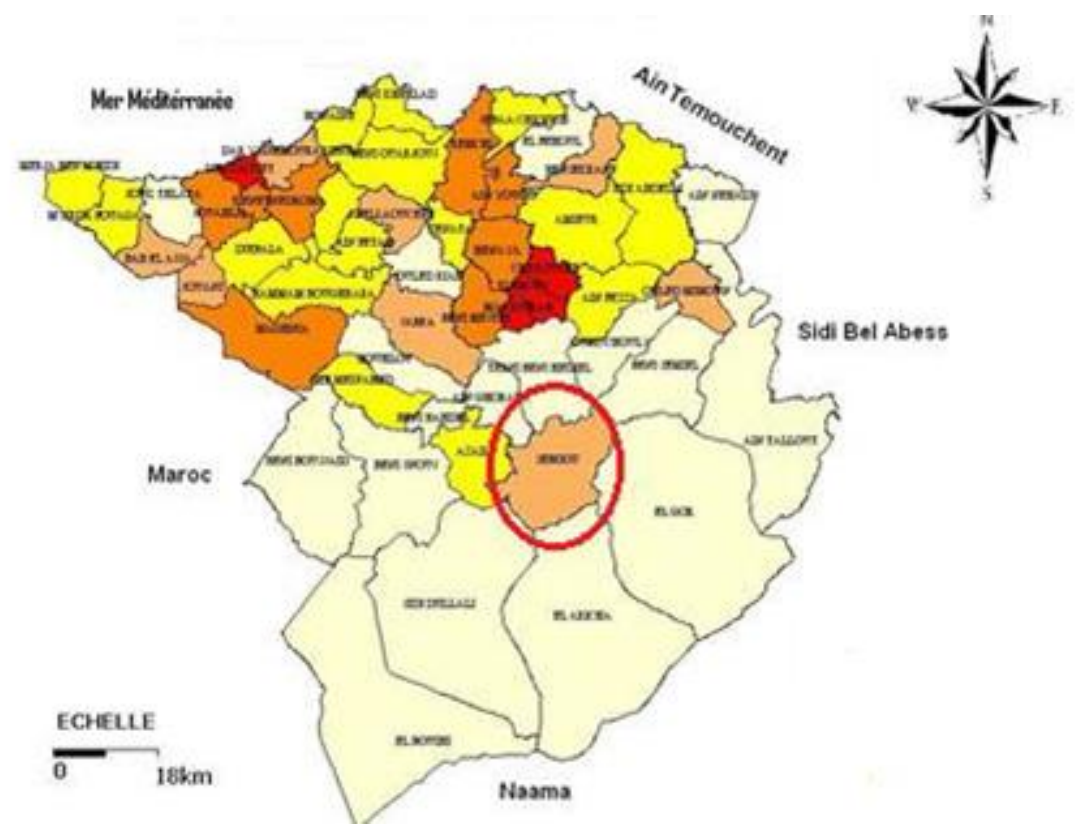

Figure 1: Geographical location of the municipality of Sebdou (P. D. A. U, 2001)

The reliefs are made up of $40 \%$ plains (or about $100 \mathrm{~km} 2$ ) and $60 \%$ mountains. The highest point is at an altitude of $1370 \mathrm{~m}$ at Diar Es Sardj. The lowest point is at an altitude of $900 \mathrm{~m}$ at the level of the agglomeration of the capital. The Sebdou plain is occupied by Plio-Quaternary alluvium, it is a very hard shell of Jurassic formation consisting mainly of dolomitic source (Ternie and Tlemcen dolomite), limestone and sandstone over the entire massive; in the middle of this set, a synclinal depression was formed extending over $40 \%$ of the municipal area, or about $100 \mathrm{~km} 2$. Sebdou occupies a protected situation of oceanic mass on the one hand and on the other hand, given its position sheltered by the mountain barrier (Mount of Tlemcen), the maritime influence is only felt very slightly. The bioclimatic data allow us to locate the study area at the level of the semi-arid bioclimatic level from the pluviothermal diagram of Emberger (1955), and to determine the period of drought using the ombrothermal diagram of Bagnouls and Gaussen (1953-1957) (figure 2). 
Table 1: Geographical data from the Sebdou meteorological station

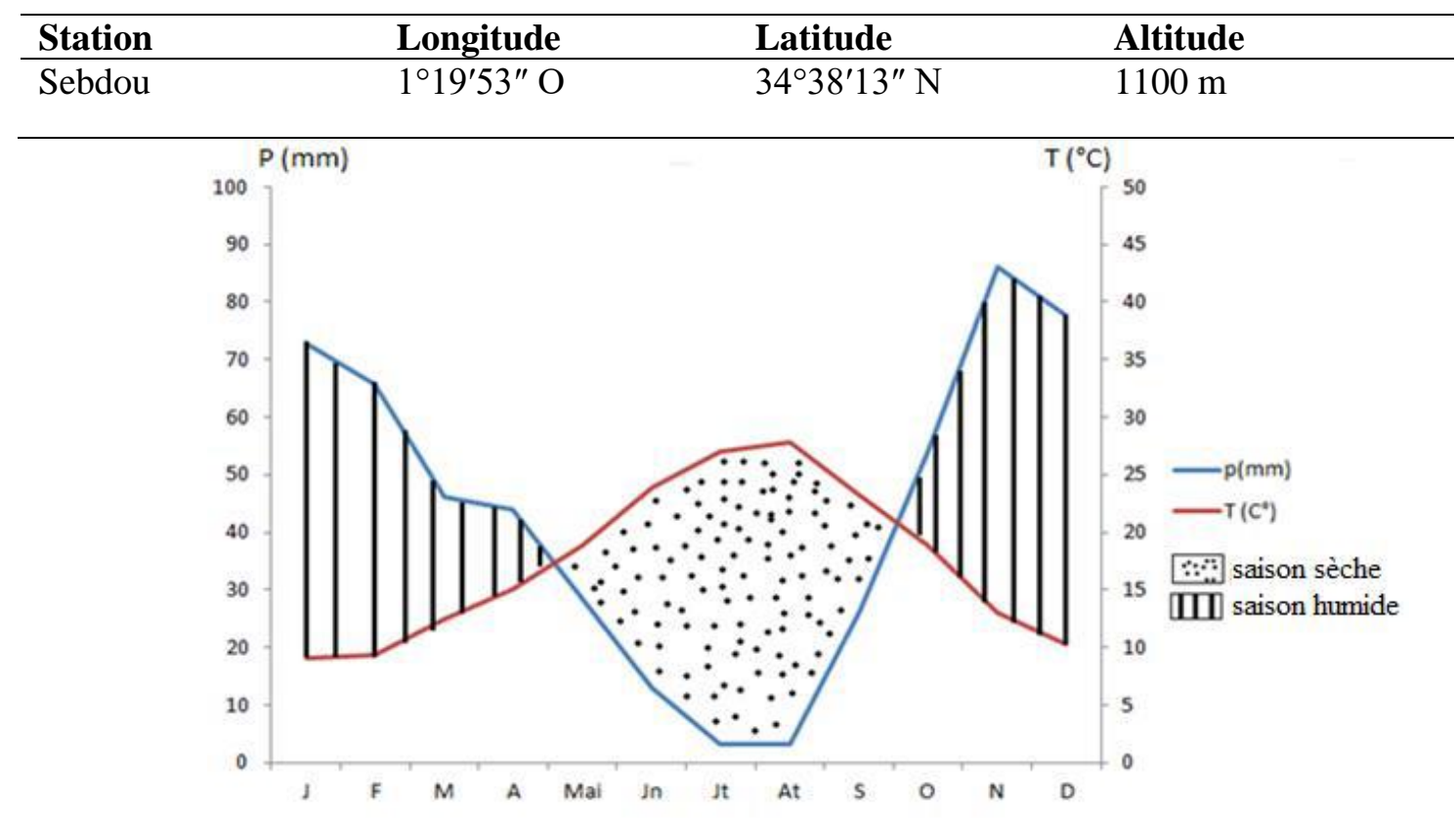

Figure 2: Ombrothermal diagram of Bagnouls and Gaussen Examination of the diagram.

Figure 2. shows that the dry period extends from the beginning of May until the end of September. It coincides with the summer season and part of the fall season. The rainy period lasts for the rest of the year and is characterized by the presence of a rainfall peak in November.

\section{Sampling}

Samplings were performed at the Sebdou cave, between July 2018 and June 2019. Fifteen samples were collected in hunting activity with a special net for this mission. Samples were taken using swabs from the oral saliva of captured animals for identification of microorganisms. Identification of microorganisms

\section{Identification on culture media}

Bat saliva samples were incubated in enrichment nutrient broth at a temperature of $37^{\circ} \mathrm{C}$ for $24 \mathrm{~h}$. After this step, the samples were inoculated in the following culture media for a first identification: nutrient agar (Oxoid, UK), MacConkey agar (Sigma-Aldrich), SS medium, King A medium, King B medium, BEA medium, Chapman medium and liquid and solid Sabouraud medium. Incubation was carried out for 24 hours at a temperature of $37^{\circ}$ C. Additionally, the presence of Salmonella spp. Was confirmed on Hektoen's medium. Purification was carried out twice in a row to eliminate any contamination.

\section{Biochemistry identification by API plates}

An "API 20E" Enterobacteriaceae Gallery (incubation at 35-37 ${ }^{\circ} \mathrm{C}$ ), a non-Enterobacteriaceae Gallery "API 20NE" (incubation at $30^{\circ} \mathrm{C}$ ) and a Staphylococcus Gallery "ID 32 STAPH" (incubation at $30^{\circ}$ C) were used for this step. $35-37^{\circ} \mathrm{C}$ ). The identification of strains after incubation was performed by the APIWEBTM identification software (Ref. 40 011).

\section{Molecular analyzes}

To refine our identification, we went to an analysis using molecular tools. A subculture of the bacterial colonies (90 colonies) obtained after culturing on specific culture media was carried out to carry out the DNA extraction. The purification of our DNA samples with the E.Z.N.A Kit, following manufacturer's instructions. 
DNA concentration was evaluated through the NANODROP 1000 (Thermofisher). Polymerase Chain Reaction (PCR) was carried out targeting the subunit 16S ribosomal RNA, using the following primers (Table 2):

Forward (F): U1 :CCAGCAGCCGCGGTAATACG

Reverse (R) : U2 :ATCGGTTACCTTGTTACGACTTC

Table 2: The PCR was performed with the following program with 10 cycles for three different increasing annealing temperature.

\begin{tabular}{|c|c|c|}
\hline Temperature & Time & Number of cycles \\
\hline $95^{\circ}$ & 10 minutes & 1 \\
\hline $95^{\circ}$ & $40 \mathrm{sec}$ & 10 \\
\hline $50^{\circ}$ & $30 \mathrm{sec}$ & \\
\hline $72^{\circ}$ & $40 \mathrm{sec}$ & \\
\hline $95^{\circ}$ & $40 \mathrm{sec}$ & 10 \\
\hline $55^{\circ}$ & $30 \mathrm{sec}$ & \\
\hline $72^{\circ}$ & $40 \mathrm{sec}$ & \\
\hline $95^{\circ}$ & $40 \mathrm{sec}$ & 10 \\
\hline $60^{\circ}$ & $30 \mathrm{sec}$ & \\
\hline $72^{\circ}$ & $40 \mathrm{sec}$ & \\
\hline $72^{\circ}$ & $5 \mathrm{~min}$. & 1 \\
\hline $4^{\circ}$ & $\infty$ & 1 \\
\hline
\end{tabular}

Subsequently, $10 \mu \mathrm{l}$ of PCR product were used for electrophoresis on $1 \%$ agarose gel to determine the size of the amplification products. Expected size of the amplicons is 1000bp in length. Visualization of the product was achieved in the G-BOX coupled with the GENSYS software. The amplifation products were than restricted with the restriction enzymes Taq1, Alu1, Hinf1 for $2 \mathrm{hrs}$ at $37^{\circ} \mathrm{C}$ : Restriction Fragment Length Polymorphism (RFLP) analysis were performed though electrophoresis on agarose gels of $2.5 \%$ to identify the samples which present the same or different electrophoretic profiles. The samples with different RFLP were selected for a sequencing of their $16 \mathrm{~S}$ genes. However, before that the DNAs go through a sequencing PCR using the U1 primers to amplify the sense strand and the U2 primer to amplify the antisense strand and undergo purification of all primers and nucleotides with the HT ExoSAP-IT KIT.

Amplicons were sequenced with the Big Dye Terminator v1.1 Cycle Sequencing kit on an ABI prism 310 genetic analyzer (Applied Biosystem)

Sequencing results were analyzed at the NCBI platform using the BLAST application to verify bacteria identification.

\section{Results and discussions}

Sampling

During our visits in the cave, we found two different species of bats on which samples were taken; namely Myotis Punicus (Vespertiliondiae, Figure 1) and Rhinolophes ferrumequinum (Rhinolophidiae, Figure 2).

Large species with large ears measuring 2.4-2.9 $\mathrm{cm}$ in length. They are very wide due to their oval shape. The shape of the tragus is very variable. The muzzle is massive. The dorsal coat is light brown to greyish while the ventral coat is white. A light golden yellow collar appears around the ears and goes down to the neck. The ears lighten in the cone of the pinna and the tragus is whitish and uniform in color. The Maghreb Murine never shows a white spot on the top of the forehead unlike the Lesser Murine Myotis blythii. Opportunistic, it feeds on Orthoptera, Coleoptera and Lepidoptera caterpillars. Considered as a gleaner, it captures its prey on the ground, on vegetation sometimes also on the ground. It is linked to open areas, meadows, lawns, grazed meadows and moors. He is rarely contacted, or even absent, from forest areas (Arthur and Lemaire 2009). 
The Greater Horseshoe Bat (Rhinolophus ferrumequinum), also known as the Greater Horseshoe Bat, Greater Horseshoe Bat or Greater Lesser Horseshoe Bat (Derwent, 1990, Meyer. 2009) is a species of bat in the Rhinolophidae family. Its distribution area extends from Spain and France, in a long strip extending to China and Japan. In Europe, it reaches its highest density in the Mediterranean basin. It is an insectivorous bat that locates and hunts insects in flight by echolocation. No sexual dimorphism is observed. It is a nocturnal species that lives in small groups in the summer and hibernates from November to April in a humid cave. The longevity is 30 years. (Csorba et al., 2003, Dietz et al., 2007).

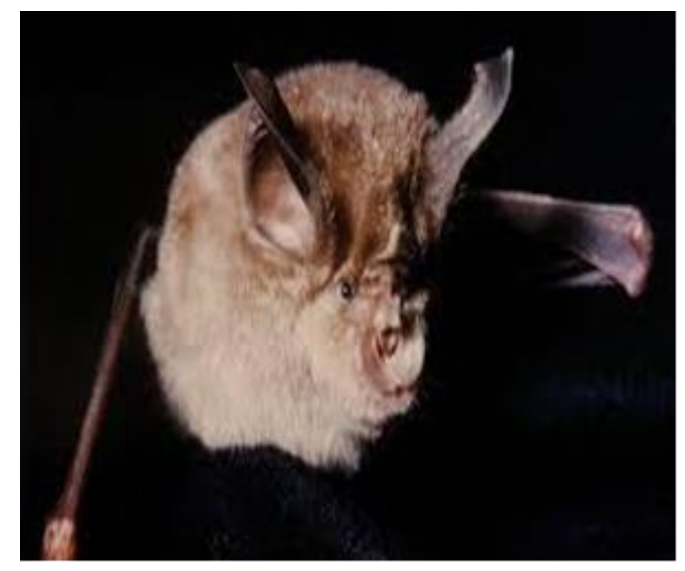

Figure 1: Rhinolophes ferrumquinum species

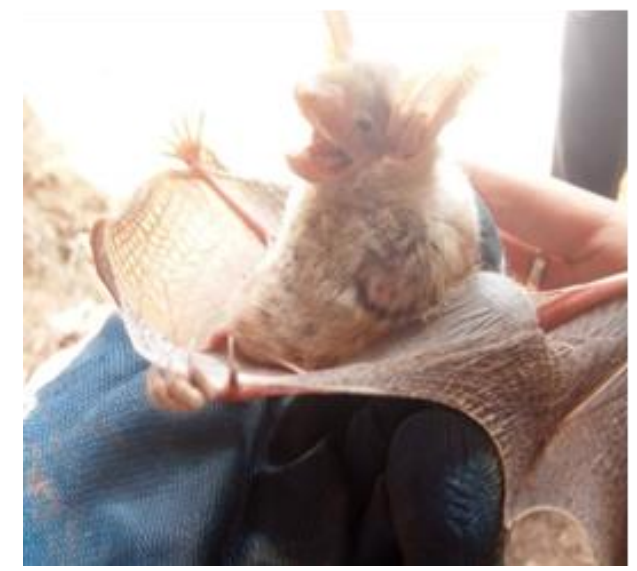

Figure 2 : Myotis Punicusspecies

\section{Identification of bacterial strains}

a. Identification by selective media: Table 3 summarizes the results of our bacteriological identification on the different bat saliva samples analyzed.

Table 3: Bacterial genus identified in bat saliva following culture on specific media.

\begin{tabular}{ll}
\hline Bacterial strains & Media used \\
\hline Staphylococcus epidermidis and Staphylococcus aureus & Chapman \\
Pseudomonas and Chryseomonas luteola & King A et King B \\
Salmonella and Shigella & SS \\
Salmonella, Shigella and coliform bacteria & Mac Conkey \\
Entérocoques & BEA \\
Salmonella, Shigellaand Yersinia & Hektoen \\
\hline
\end{tabular}

b. Identification by API plates: To have a more specific and precise result we used the API20E plates for Enterococci, API Staph, API Strept to identify the colonies to be identified from the culture media used in the previous step. The results obtained by the plates were interpreted (to identify the bacterial species) using API web software. The results of this step are summarized in Table 4.

A total of 14 species of bacteria were more or less precisely identified using culture media and API plates from 15 saliva samples from two species of bats. It should be noted that one of the different strains analyzed on the plates presented a code that could not be identified by the API web software. 
Louhibi et al, 2021. Genet. Biodiv. J , 5 (2) ; 63-71

Table 4: Correspondence of codes on APIweb

\begin{tabular}{lll}
\hline MEDIUM & CODE & SPECIES \\
\hline Mac Conkey & 7356573 & Raoultella ornithinolytica $85 \%$ \\
Mac Conkey & 7345773 & Enterobacter cloacae $94 \%$ \\
& 7344773 & Raoultella ornithinolytica $85 \%$ \\
Hektoen & 7345773 & Raoultella ornithinolytica $84.1 \%$ \\
& 344773 & Raoultella ornithinolytica $85.2 \%$ \\
Mac Conkey & 7344773 & Raoultella ornithinolytica $85.2 \%$ \\
Mac Conkey & 3206773 & Serratia ficaria $76 \%$ \\
Hektoen & 6355773 & Raoultella ornithinolytica $99.8 \%$ \\
Hektoen & 7355773 & Raoultella ornithinolytica $99.8 \%$ \\
SS & 7345573 & Suterobacter cloacoe $38.4 \%$ \\
& & Suterobacter sakazakii $36.9 \%$ \\
Mac Conkey & 7345573 & Enterobacter cloacae $38.4 \%$ \\
SS & 0040000 & Not found Code \\
Hektoen & 7345573 & Enterobacter cloacae $82 \%$ \\
Mac Conkey & 6347773 & Serratia odorifera $99.9 \%$ \\
Hektoen & 7740372 & Salmonella charizonae $92 \%$ \\
SS & 7744572 & Salmonella choleraesuis $\mathrm{ssp}$ arizonae $99.6 \%$ \\
Mac Conkey & 7746573 & Serratia odorifera $99.9 \%$ \\
\hline
\end{tabular}

- PCR Analysis

A subculture of the bacterial colonies (90 colonies) obtained after culturing on specific culture media was carried out to carry out the DNA extraction (Figure 5).

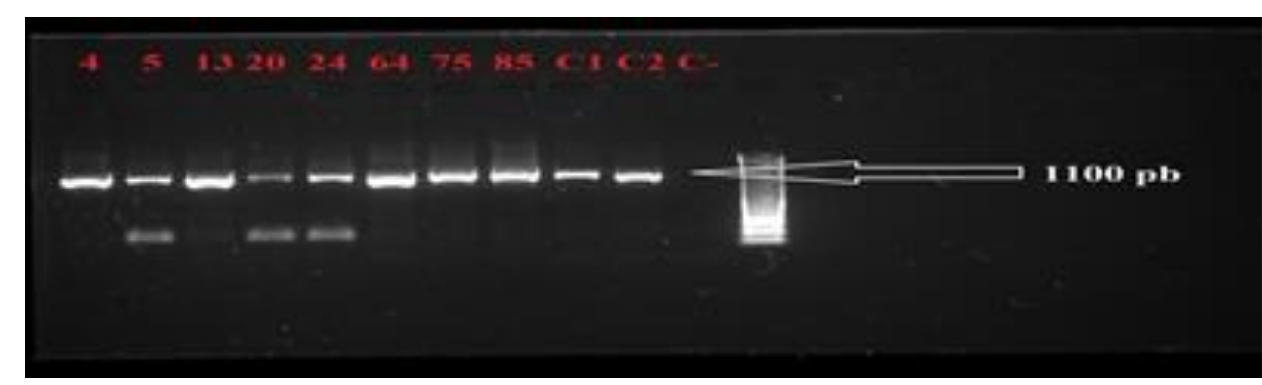

Figure 5: Post-PCR electrophoresis by universal primers on the samples after purification.

The results of the PCR-RFLP demonstrated that among our extracted DNA samples there were those that presented the same electrophoretic profile and are therefore probably the same bacterial species (Figure 6 and 7). 


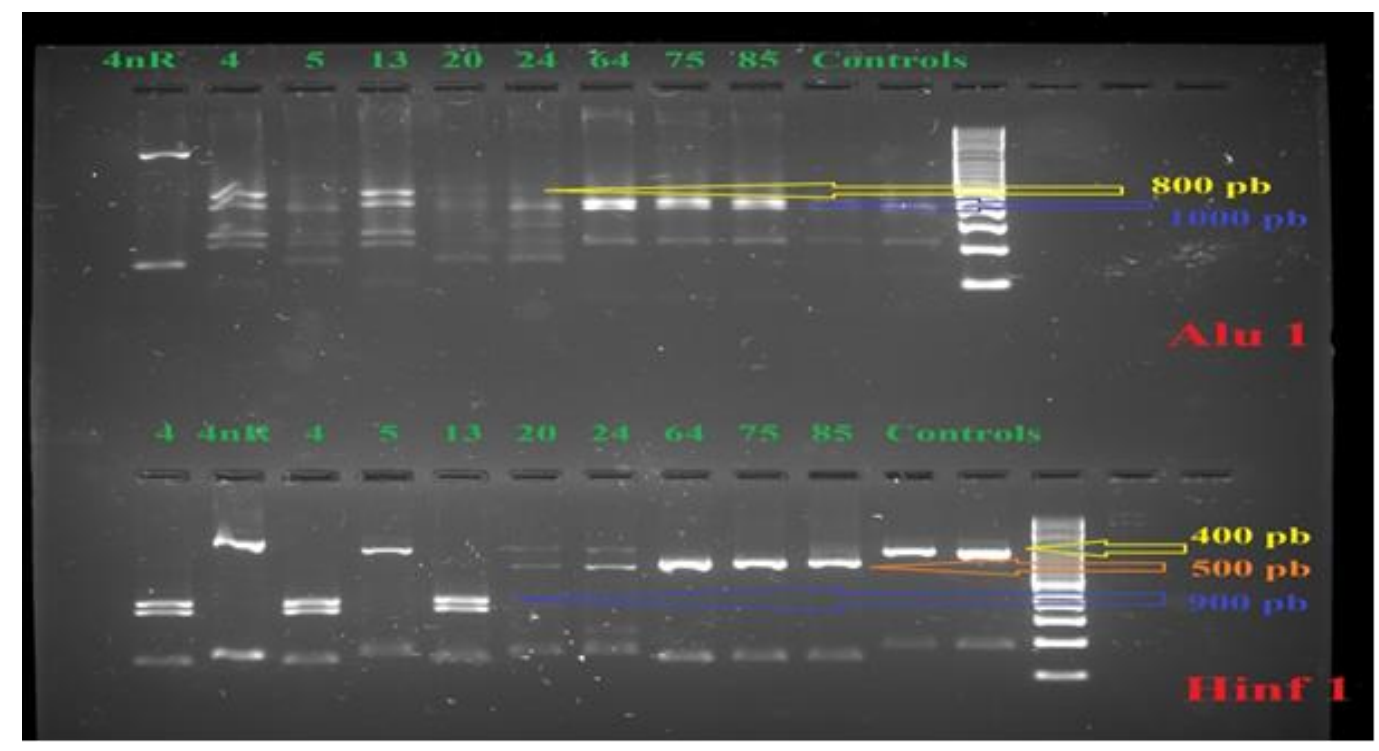

Figure 6 : Electrophoresis post-RFLP (Alu1,Hinf1)

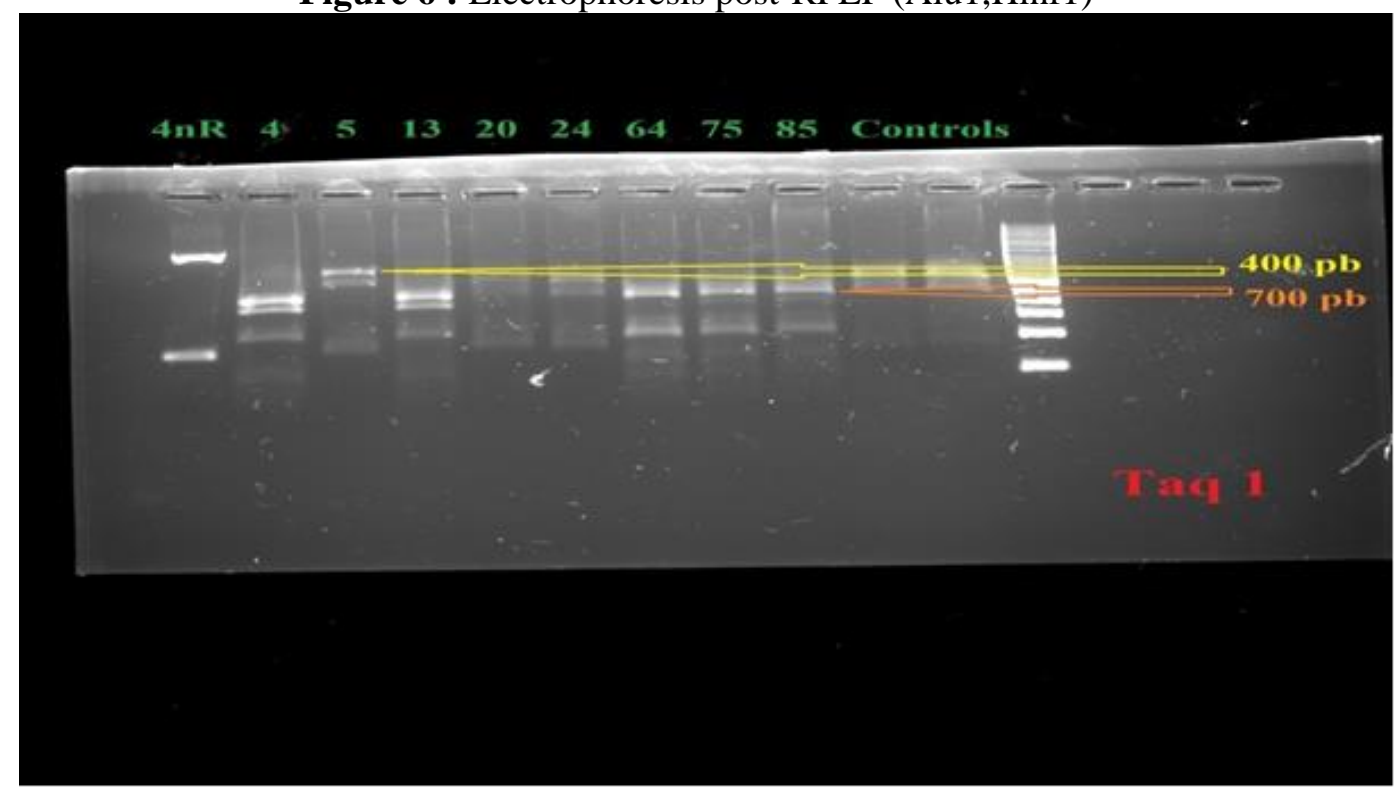

Figure 7: Electrophoresis post-RFLP (Taq1)

The results of PCR-RFLP allowed us to choose from each electrophoretic group a single sample to be sequenced for the $16 \mathrm{~S}$ gene (this procedure was adopted due to budget restriction). In total 12 samples representing the 12 electrophoretic groups (Table 5) obtained were passed to the sequencer where only 7 samples could be sequenced.

Table 5: Sample content of the seven PCR-RFLP Electrophoretic group.

\begin{tabular}{ll}
\hline Electrophoretic groups & Sample number \\
\hline Group 1 & 4,13 \\
Group 2 & 14,22 \\
Group 3 & 20,24 \\
Group 4 & $51,52,56,70,76$ \\
Group 5 & $64,75,85$ \\
Group 6 & 80,91 \\
Group 7 & 100,102 \\
\hline
\end{tabular}


The sequences thus obtained were analyzed on the NCBI platform. BLAST software was used to identify their taxonomic affiliations. The bacterial species identified are: Proteus mirabilis: samples $\mathrm{n}$ ${ }^{\circ} 4$ (group 1). Enterobacter ludwigii: samples No. 51 (group 4). Klebsiella oxytoca: samples No. 102 (group 7). It should be noted that for some sequence no correspondence was identified on NCBI, which means that we are probably in the presence of new species. 14, 22: probably same species, group 2 (not identified). 20, 24: probably same species, group 3 (not identified). 64, 75, 85: probably same species, group 5 (not identified). 80, 91: probably same species, group 6 (not identified).

In a study by Judith C. M. et al., 2019 conducted in Netherlands, the authors investigated the fecal microbiota from common pipistrelle (Pipistrellus pipistrellus; $\mathrm{n}=3$ ), Daubenton's bat (Myotis daubentonii; $\mathrm{n}=3$ ), serotin bat (Eptesicus serotinus ; $\mathrm{n}=1$ ), whiskered bat (Myotis mystacinus; $\mathrm{n}=1$ ), Geoffroy's bat (Myotis emarginatus; $\mathrm{n}=1$ ) and Natter's bat (Myotis nattereri; $\mathrm{n}=1$ ) by followed by polymerase chain reaction and denaturing gel electrophoresis (PCR-DGGE) targeting the 16S rDNA and subsequent sequencing. The species found belonged mainly to the genera Carnobacterium, Serratia, Pseudomonas, Enterococcus and Yersinia. The presence of opportunistic pathogens Citrobacter freundii, Escherichia coli, Enterococcus faecalis, Serratia fonticola and Rahnella aquatilis has also been recorded. This was carried out using fecal samples from 37 insectivorous bats of different species from the Netherlands studied. This study revealed a lower diversity in bacterial species (5 genera) than our study which was carried out on only two species and on only two samples (10 genera), this result can be explained by the fact that our study was carried out on saliva while this study was performed on fecal matter. On the other hand, Sunil B. et al., 2016 on the bacterial analysis of guano (on the species Rousettusleschenaultii) identified a total of 105 species belonging to 37 different genera and 4 bacterial phyla, that is ie proteobacteria, firmicutes, actinobacteria and bacteroids.

\section{Conclusion}

Our work is among the first studies carried out on the identification of microorganisms in bat saliva in the world, which makes the latter a very original study. Our study was carried out in the southern region of the wilaya of Tlemcen (Sebdou) at the level of a cave located in a mountain 300m deep. The identification of the microorganisms in the saliva of the bat was carried out on 90 samples with biochemical and molecular biology techniques. A total of 17 species of bacteria could be identified. Certain biochemical profile and DNA sequences could not be identified and testify to the probable presence of new bacteria. This work deserves more in-depth investigations to identify other species of the microbial and fungal flora, in particular by the NGS technique, and to identify probable important agroecological and agro-industrial functions.

\section{References}

Arthur L. Lemaire M. 2009. Les Chauves-souris from France, Belgium, Luxembourg and Switzerland. Biotope, Mèze (Parthénope Collection); MNHN, Paris, 544p.

Arthur L. Lemaire M. Avril BWP 1997. Le Minioptére de Schreibers : analyse des résultant de baguage de 1936 à 1970.Thèse de doctorat vétérinaire, Toulouse, p 128.

Bertrand JC. Caumette P. Lebaron P. Matheron R. Normand P. 2011. Ecologie microbienne : Microbiologie des milieux naturelset anthropiques. Presses universitaires de Pau et des $\mathrm{Pa}$ s de l'Adour (France). Pp1002.

Chastel C 2014. Middle East respiratory syndrome (MERS): bats or dromedary, which of them is responsible? Bull. Soc. Pathol. Exot.107:69-73.

Csorba G. Ujhelyi P. Thomas N 2003. Horseshoe Bats of the World (Chiroptera: Rhinolophidae), Alana Books.

Derwent 1990. Thesaurus of agricultural organisms: pests, weeds and diseases, Volume 1. Derwent Publications, Ltd. CRC Press editions. 1529 pages. (ISBN 0-412-37290-8), 9780412372902.

Dietz C. Von Helversen O. NillD. (Dubourg-Savage translation), The encyclopedia of bats in Europe and North Africa, delachaux et niestlé, (2007) 2009, 400 p.

Guangwen L. Di L 2012.SARS-like virus in the Middle East: a truly bat-related coronavirus causing human diseases. Protein Cell;3(11):803. 
Holly L. Lutz. Elliot W. Jackson. Paul W. Webala. Waswa S. Babyesiza. Julian C. Kerbis P. Terrence CD. Bruce DP. Jack AG 2019. Ecology and Host Identity Outweigh Evolutionary History in Shaping the Bat Microbiome. mSystems. 4(6): e00511-19 DOI: $10.1128 / \mathrm{mSystems.00511-19.}$

Judith CM. Wolkers R. Katharina R. Thijs B. Wilma C. Hazeleger 2019. Fecal Bacterial Communities in Insectivorous Bats from the Netherlands and Their Role as a Possible Vector for Foodborne Diseases. Acta Chiropterologica, 20(2):475-483 .https://doi.org/10.3161/15081109ACC2018.20.2.017

Meyer C. 2009. Dictionary of Animal Sciences. Montpellier, France, Cirad.

O'Shea TJ. Cryan PM. Cunningham AA. Fooks AR. Hayman DTS. Luis AD. Peel AJ. Plowright RK. Wood JLN 2014. Bat flight and zoonotic viruses. Emerging Infectious Diseases; 20(5): 741745.).

Sunil B. Shrikant SB. Mangesh V. Suryavanshi SP. Yogesh S 2016. Shouche. Microbiome analysis reveals the abundance of bacterial pathogens in Rousettus leschenaultii guano. Scientific Reports.6 : 36948 (2016). 